\title{
CURRÍCULO E DIFERENCIAÇÃO PEDAGÓGICA - uma prática de exclusão?
}

\author{
Márcia Marin ${ }^{1}$ \\ Patrícia Braun²
}

\section{RESUMO}

Este artigo propõe a reflexão sobre o conceito de diferenciação pedagógica como uma estratégia curricular para a aprendizagem escolar de estudantes que exigem respostas educativas que atendam suas peculiaridades, destacamos aqui pessoas com deficiência intelectual e com autismo, que compõem nossa experiência profissional como professoras da educação básica em escolas públicas. O nosso intuito é trazer à tona a tensão que se estabelece entre a garantia de igualdade de direitos em contraponto aos procedimentos e recursos de ensino diferenciados. Algumas questões se apresentam nesse contexto: em que medida fazer 'tudo igual ao mesmo tempo' promove a aprendizagem de estudantes com diferenças significativas em seu desenvolvimento? E ao planejar ações diferenciadas estaremos reforçando a exclusão? Concebemos que diferenciação pedagógica pressupõe a promoção de equidade. E, para melhor pensar práticas curriculares, trazemos os princípios de Desenho Universal para a Aprendizagem (DUA) como uma possibilidade de planejamento favorável à promoção de ações pedagógicas diversificadas e equânimes para todos. A partir do diálogo entre reflexões teóricas e relatos de experiências, apresentamos práticas de diferenciação pedagógica em contextos de educação básica, como exemplos a fomentar o diálogo docente sobre inclusão, diversidade e acessibilidade ao currículo.

Palavras-chave: Práticas curriculares. Diferenciação pedagógica. Desenho Universal para a Aprendizagem.

\section{CURRICULUM AND PEDAGOGICAL DIFFERENTIATION - a practice of exclusion?}

\begin{abstract}
This article proposes a reflection on the concept of pedagogical differentiation as a curriculum strategy for students' learning that requires educational responses that

1 Doutora em Educação (Universidade do Estado do Rio de Janeiro-UERJ). Professora Titular aposentada do Colégio Pedro II. Professora Adjunta da Fundação Técnico-educacional Souza Marques - Rio de Janeiro/Brasil. Orcid iD: https://orcid.org/0000-0002-5365-6834. E-mail: marinvianna2014@gmail.com

2 Doutora em Educação (Universidade do Estado do Rio de Janeiro-UERJ). Professora Adjunta do Instituto de Aplicação Fernando Rodrigues da Silveira CAp-UERJ - Rio de Janeiro/Brasil. Orcid iD: https://orcid.org/0000-0002-5666-2420. E-mail:
\end{abstract} braunpatricia09@gmail.com 
meet their peculiarities. We highlight here people with intellectual disabilities and autism, who make up our professional experience as teachers of basic education, in public schools. Our aim is to bring to the forefront the tension that is established between guaranteeing equal rights against differentiated teaching procedures and resources. Here are some questions: How does doing 'all the same at the same time' promote the learning of students with significant differences in their development? And by planning different actions are we reinforcing exclusion? We conceive that differentiation in teaching presupposes the promotion of equity. And to better think about curricular practices, we bring the principles of Universal Design for Learning (DUA) as a possibility of planning favorable to the promotion of diverse and equitable pedagogical actions for all. From the dialogue between theoretical reflections and experience reports, we present practices of pedagogical differentiation in basic education contexts, as examples to foster teacher dialogue on inclusion, diversity and accessibility to the curriculum.

Keywords: Curriculum Practices. Pedagogical differentiation. Universal Design for Learning.

\section{CURRICULUM Y DIFERENCIACIÓN PEDAGOGICA - ¿una práctica de exclusión?}

\section{RESUMEN}

Este artículo propone una reflexión sobre el concepto de diferenciación pedagógica como una estrategia curricular para el aprendizaje de los estudiantes que requiere respuestas educativas que respondan a sus peculiaridades. Destacamos aquí las personas con discapacidad intelectual y autismo, que conforman nuestra experiencia profesional como profesores de educación básica, en las escuelas públicas. Nuestro objetivo es poner en primer plano la tensión que se establece entre garantizar la igualdad de derechos frente a procedimientos y recursos de enseñanza diferenciados. Aquí hay algunas preguntas: ¿ Cómo hacer 'todo lo mismo al mismo tiempo' promueve el aprendizaje de los estudiantes con diferencias significativas en su desarrollo? ¿Y al planificar diferentes acciones estamos reforzando la exclusión? Concebimos que la diferenciación en la enseñanza presupone la promoción de la equidad. Y para pensar mejor sobre las prácticas curriculares, presentamos los principios del Diseño Universal para el Aprendizaje (DUA) como una posibilidad de planificación favorable para la promoción de acciones pedagógicas diversas y equitativas para todos. A partir del diálogo entre reflexiones teóricas e informes de experiencias, presentamos prácticas de diferenciación pedagógica en contextos de educación básica, como ejemplos para fomentar el diálogo entre docentes sobre inclusión, diversidad y accesibilidad al currículo.

Palabras clave: Prácticas curriculares. La diferenciación pedagógica. Diseño universal para el aprendizaje. 


\section{IDEIAS INICIAIS: CURRÍCULO E A ESCOLA PARA TODOS}

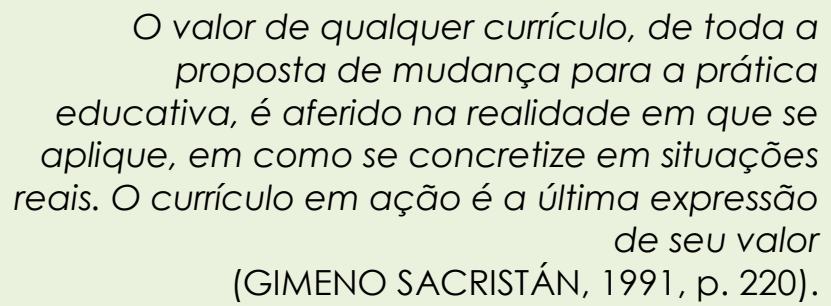

O vocábulo 'currículo' vem da palavra currere, referindo-se à carreira, um percurso a ser seguido, conforme aponta Gimeno Sacristán (2000). Concebemos, então, currículo como caminho que se trilha, o que pressupõe: movimento e envolve, de forma dinâmica e imbricada, conteúdos previamente selecionados a serem ensinados e aprendidos; experiências de aprendizagem escolares a serem vividas pelos estudantes; planos pedagógicos elaborados por professores, escolas e sistemas educacionais; objetivos a serem alcançados por meio do ensino; processos de avaliação; e, juntamente com isso tudo e de modo dialogado, o contexto sociocultural da comunidade escolar; vivências e conhecimentos que os estudantes já têm; necessidades e interesses coletivos. Em síntese, currículo escolar está aqui posto como um instrumento vivo a serviço de docentes e estudantes para a efetivação de aprendizagens significativas.

'Currículo e a escola para todos' é o tema inicial para situarmos este texto, que pretende de modo geral promover uma reflexão sobre a necessidade cada vez mais urgente de criar um caminho que possa ser percorrido de modos variados e que dê alternativas de acesso ao conhecimento.

Em conjunto com Magalhães e Soares (2016, p. 1129), entedemos que "os processos de escolarização são significativamente culturais. [...] Interpelam, assim, formas de pensar o conhecimento e transmiti-lo, bem como formas de pensar quem é o estudante e como ele aprende".

Quem é o estudante? Como ele aprende? O quê e como ensinar? É possível afirmar que o planejamento docente revela escolhas feitas com base em valores culturais e sociais, contextualizadas num tempo histórico. 
Atualmente pensar em um currículo para diversidade, realidade inerente às salas de aula das escolas públicas, é propor um ensino para todos e para cada um.

Nesse contexto, as ações educativas desenhadas no currículo são entendidas como parte de um processo social com "objetivos específicos, objetivos esses que traduzem as opções estratégicas e as prioridades das políticas educativas que, em determinado momento, se afirmam" (MORGADO, 2010, p. 17). E é nessa ação docente, na prática de ensino para promover a aprendizagem, que o currículo expressa seu valor (GIMENO SACRISTÁN, 1991).

Além disso, outro fator relevante, relacionado a essas ideias iniciais, diz respeito à organização do tempo e do espaço escolar, pois reflete diretamente sobre as condições de ensino e de aprendizagem e na ação docente. Saviani (2003) diz que há o "tempo de ensino" - relativo ao professor, que envolve a sua formação inicial e continuada, o preparo, a execução e avaliação das propostas pedagógicas; e há o "tempo de aprendizagem" - relativo ao estudante, aos diferentes ritmos e experiências desses, de forma a perceber a intervenção necessária entre o que ele consegue realizar sozinho e aquilo que exige a mediação pedagógica. Devido a esses tempos que diferem entre si, mas que são indissociáveis no processo escolar, há de se arquitetar espaços e recursos apropriados que viabilizem o desenvolvimento do currículo para todos os envolvidos.

Mas quem são os envolvidos?

São professores, gestores escolares, técnicos da educação, e, prioritariamente, estudantes, para os quais o currículo é desenhado, por isso não há como desconsiderar a grande variação de percurso que eles apresentam, em razão das diferenças inerentemente humanas.

Por essa via de reflexão, observamos o acúmulo e a complexidade de discussões políticas e educacionais que envolvem currículo, que não se esgotam por aqui.

Somando isso ao nosso foco, que é a escolarização de pessoas com deficiência intelectual e autismo, a problemática se amplia. Se outrora a 
escolarização desses ocorria por via da escola especial, com estruturas, tempos e espaços diferentes do praticado nas escolas comuns, nos dias atuais, a perspectiva de inclusão escolar e a presença desses estudantes, e de tantos outros, antes fora da escola comum, revelam fragilidades que questionam um currículo que não envolve a todos.

Articular um currículo para todos não significa igualar condições de ensino, mas torná-las equânimes. "Se igualamos, novamente massificamos, desconsideramos as demandas que cada estudante pode apresentar e, por consequência, acabamos como agentes diretos da exclusão" (BRAUN, 2010, p. 46).

Em relação às pessoas que apresentam deficiência, por exemplo, a educação passa a ser "olhada" timidamente, no Brasil, a partir de ideiais liberais disseminados no país entre o fim do século XVIII e início do século XIX (JANNUZZI, 2006), quando são consideradas 'educáveis' e 'currículos especiais' são organizados, principalmente para a área de deficiência intelectual. Não vamos nos estender nessa análise, por priorizarmos outras discussões, mas vale dizer que ainda estamos a tentar superar a ideia da ação 'de caridade' nas práticas escolares junto aos estudantes com deficiência ou com autismo.

\begin{abstract}
Assim, se é verdade que um período político ditatorial e conservador pôde oferecer meios para que o interesse privado se impusesse em detrimento ao direito da maioria e de incentivo ao âmbito do assistencialismo, o fato de ter sido superado não significa que tenhamos conseguido reverter tanto o privilegiamento das elites quanto o assistencialismo dos "infortunados". Os últimos rumos das atuais políticas nacionais colocam em risco os avanços que tinham sido obtidos no campo educacional após a queda do regime de 1964, especialmente por meio de pressões dos movimentos organizados em prol da melhoria da qualidade e da democratização da educação pública (BUENO; LEHMKHUL; GOES, 2019, p. 16).
\end{abstract}

A partir dessas reflexões iniciais é importante ter a clareza de que existem demandas específicas para estudantes com deficiência intelectual e autismo, que exigem estratégias diferenciadas a serem consideradas num planejamento curricular, e que, além disso, um currículo para a diversidade pode atender uma escola para todos. Como dito por Nunes e Madureira 
(2015, p. 129), "importa sobretudo equacionar processos pedagógicos que possibilitem, quer uma efetiva participação nos diferentes contextos, quer a realização de aprendizagens por parte de todos".

\section{CURRÍCULO, DIFERENCIAÇÃO E DESENHO UNIVERSAL PARA APRENDIZAGEM: interfaces possíveis?}

A esta linha de análise e reflexões, somamos a ideia de diferenciação pedagógica como uma estratégia curricular apropriada à inclusão escolar de estudantes com deficiência intelectual e estudantes com autismo na escola comum.

Seguem uns parênteses considerados necessários por nós.

\section{(Por que Deficiência intelectual e transtorno do espectro do autismo?)}

Em uma análise realizada por Marin; Mascaro; Maretti e Braun (2015), ficou evidenciado que alunos com deficiência intelectual (DI) e com transtorno do espectro do autismo (TEA) "requerem maior intervenção imediata nas ações ocorridas durante a aula, necessitam de interlocução constante e os professores apontam prioridades para o apoio no decorrer das atividades escolares" (p.59).

Além disso, esses estudantes são os que marcam nossa trajetória docente no ensino fundamental de escolas públicas, pois têm sido nosso maior desafio cotidiano no que tange a promover um ensino que garanta aprendizagem escolar.

Escolhemos, nesse texto, não apresentar definições e conceituações referentes a essas áreas - DI e TEA, mas esclarecemos que adotamos uma abordagem social em relação às práticas escolares, explicando isso, de um modo sintético, a partir das considerações de Valle e Connor (2014) que:

Sem querer simplificar demais, podemos pensar no modelo médico como preocupado, principalmente, com a identificação e a mudança do aluno que não se enquadra no contexto escolar (isto é, baseia-se em uma percepção de que a criança é intrinsecamente deficiente), enquanto o modelo social se concentra na adaptação do contexto escolar, de modo que este se torne adequado ao aluno (isto é, baseia-se na percepção de que o ambiente pode incapacitar a criança) (p. 13, grifo nosso). 
Ou seja, na escola, cada sujeito da aprendizagem precisa ser conhecido em contexto, na compreensão de suas habilidades, possibilidades e de como se relaciona com o conhecimento, de como aprende melhor; deste modo, recursos e estratégias são elaborados como apoios, por essa razão poderão ser 'personalizados', feitos 'sob medida', e, certamente, servirão a outros estudantes das classes comuns.

Diante de tal configuração, cabe pensar a diferenciação pedagógica como uma "possibilidade de enriquecimento curricular [...] em contraposição à ideia de redução, ou empobrecimento dos conteúdos" (GARCIA, 2006 apud MAGALHÃES e SOARES, 2016, p.1131).

Por isso, apontamos a relevância de pensar o currículo de uma forma mais flexível, aberta às diferenças de todos, com ênfase à "importância de os professores reconhecerem as limitações de seus estudantes, mas desenvolverem uma prática pedagógica que não seja orientada pelas impossibilidades" (MAGALHÃES, 2011, p. 81).

Por fim, reconhecemos que atualmente as lacunas da escola se configuram muito mais pela situação flagelada dos sistemas políticos e econômicos e de suas estruturas, do que pela condição do desenvolvimento de um ou outro estudante. Aliás, o que observamos é a condição real da diversidade de estudantes ser apontada como um obstáculo, ao invés de uma riqueza, por condições externas que não favorecem ninguém, inclusive limitam a ação docente.

Fechando os parênteses, que serviram para uma melhor contextualização, voltemos a algumas questões centrais do nosso texto: em que medida fazer 'tudo igual ao mesmo tempo' promove a aprendizagem de estudantes com diferenças significativas em seu desenvolvimento? $\mathrm{E}$, ao planejar ações diferenciadas, estaremos reforçando a exclusão?

Essa tensão nos impulsionou a compreender que fazer diferente não se traduz necessariamente em fator de exclusão. Os estudos e conceitos referentes à diferenciação no âmbito da educação nos ajudaram a compor e a reforçar práticas cotidianas em favor de estudantes que aprendem por 
caminhos diversos, diferenciados. Concebemos, ainda, que diferenciação pedagógica pressupõe a promoção de equidade. No decorrer dos estudos e do tempo, também conhecemos a perspectiva do Desenho Universal para a Aprendizagem (DUA), que somamos às nossas inquietações, pois tem como pressuposto central a promoção de práticas pedagógicas diversificadas e equânimes.

Vamos discorrer um pouco sobre esses temas e descrever algumas ações cotidianas, que são repletas de desafios e dúvidas, mas têm o compromisso de promover o ensino para cada estudante que se apresentou e se apresenta em nossa trajetória profissional, pois buscamos constantemente responder às nossas urgências por ensinar e as dos estudantes por aprender.

O conceito de diferenciação foi incorporado às nossas tentativas de realizar sempre um melhor trabalho profissional, inicialmente, a partir de algumas perspectivas que encontramos na área da Sociologia da Educação, principalmente discutidas por Perrenoud $(1999 ; 2001)$ e por André (1999).

Para melhor situar o leitor, indicamos que diferenciação pedagógica fica, então, compreendida como a ação de "organizar as interações e atividades de modo que cada aluno se defronte constantemente com situações didáticas que Ihe sejam as mais fecundas" (PERRENOUD, 1999, p.28). André (1999, p.12) esclarece essa concepção:

As pedagogias diferenciadas não voltam às costas para o objetivo primordial da escola que é o de tentar garantir que todos os alunos tenham acesso a uma cultura de base comum. (...) considerar as diferenças é encontrar situações de aprendizagem ótimas para cada aluno, buscando uma educação sob medida. (...) procura-se substituir o ensino individualizado, em que cada aluno desenvolve isoladamente suas tarefas, por uma diferenciação no interior de situações didáticas abertas e variadas, confrontando cada aluno com aquilo que é obstáculo para ele na construção dos saberes.

Pedagogias diferenciadas têm como base o currículo escolar, de modo que todos tenham acesso àquilo que a escola se propõe a ensinar, na promoção de situações didáticas favoráveis à condição de cada 
estudante. Essa disposição equânime em fazer diferente para atender às diferenças, pode traduzir-se como uma "educação sob medida". Como novamente esclarece André (1999, p. 22):

Diferenciar é dispor-se a encontrar estratégias para trabalhar com os alunos mais difíceis. Se o arranjo habitual do espaço da sala não funciona com esses alunos, se os livros e os materiais didáticos não são adequados para eles, se, enfim, as atividades planejadas não os motivam, é preciso modificá-las, inventar novas formas, experimentar, assumir o risco de errar e dispor-se a corrigir.

Buscando outros autores, encontramos discussões que nos fizeram pensar, repensar e partir para outras práticas possíveis (GARCÍA; BEATÓN, 2004; ROLDÃO, 2003a; 2003b; SANTOS, 2009; TOMLINSON, 2008), envolvendo a ideia de diferenciação calcada no princípio de equidade (RODRIGUES, 2013).

Para Santos (2009, p. 52):

[...] a diferenciação pedagógica constitui-se como uma resposta orientada pelo princípio do direito de todos à aprendizagem, essencial para dar resposta à heterogeneidade de alunos que frequentam a escola actual.

A autora distingue três níveis de diferenciação: institucional - macro, no âmbito dos sistemas de ensino, como são os cursos regulares e os técnicos profissionalizantes; externa - meso, na esfera da organização escolar, como turmas de aceleração para alunos fora da faixa etária; e interna - micro, no domínio do cotidiano da sala de aula, como intervenções na rotina escolar. A interna é a que buscávamos, para intervir na rotina, tornando-a mais acessível ao maior número de estudantes. Pudemos reforçar nossas premissas e ações ao estudar e refletir com e no cotidiano. Verificamos que:

O conceito de diferenciação curricular vem ganhando crescente centralidade no discurso educativo e na literatura curricular, [...] referenciando a diversas matrizes de análise, que se reportam quer à defesa de uma construção curricular inteiramente contextualizada nos meios de pertença dos alunos, quer à procura de vias escolares diferentes para alunos pertencentes a grupos ou culturas diversos, quer ao esforço praxiológico para diferenciar metodologias e ritmos 
de ensino face a alguns grupos de alunos integrados na escola regular (ROLDÃO, 2003a, p. 152).

A mesma autora apontou, com base em suas investigações, que é recorrente a fala de docentes apontando a diferenciação como estratégia indispensável. "O reconhecimento da necessidade de ensinar de forma diferente alunos com situações de partida diferentes é hoje convocado a todos os níveis do discurso: o político, o investigativo, o dos normativos, o do senso comum dos professores" (ROLDÃO, 2003a, p. 159).

Tomlinson (2008, p. 72) é outra autora que favoreceu, com suas considerações, a análise de práticas pedagógicas em situações de inclusão:

O objectivo do ensino diferenciado é assegurar que todos desenvolvem as capacidades e áreas de conhecimentos essenciais, a partir dos seus próprios pontos de partida. (...) Numa sala de aula com ensino diferenciado, o professor avalia e monitoriza de perto capacidades, níveis de conhecimento, interesses e métodos mais eficazes de aprendizagem para todos os alunos e planifica, em seguida, as aulas e as tarefas tendo em mente todos esses diferentes níveis. (...) Uma aula diferenciada designada por um professor reflecte o entendimento actual que este tem sobre o que a criança deve desenvolver a nível de conhecimento e capacidades. Esse entendimento é evolutivo e mudará durante o ano lectivo. (...) Um dos seus objetivos deve ser ajudar cada aluno a tornar-se cada vez mais autónomo.

Na prática, os professores são os responsáveis pela efetivação de uma proposta como essa, conforme afirma Santos (2009, p. 57): "por em acção uma prática de diferenciação pedagógica é exigente para o professor. Exigente, não porque roube tempo para o cumprimento do programa - não há cumprimento se não houver aprendizagem -, mas sim porque requer um conhecimento profundo dos alunos".

Reconhecemos e sabemos que, com tantas tarefas superpostas, é um desafio docente conhecer necessidades, limites e possibilidades dos estudantes, pois na organização de horários por disciplinas, há professores que têm contato com a turma, no máximo, uma vez por semana por 90 minutos, por exemplo. 
Outro fator é o grande número de alunos por turma, isso porque os professores não conseguem se aprofundar nos casos de alunos que exigem atenção específica. Conhecer o aluno requer maior interação, mais tempo e práticas pedagógicas que favoreçam isso.

Diante do exposto, vê-se que diferenciação pedagógica não é uma ação improvisada, nem simples; ao contrário, requer planejamento, avaliação das condições de aprendizagem dos estudantes, seleção de material didático específico, entre outras coisas.

Não é possível desenvolver uma diferenciação pedagógica que contribua para a aprendizagem dos alunos pensada sobre 0 momento e, portanto, surgida ao acaso e de forma espontânea. [...] Estas decisões estão dependentes dos objectivos de aprendizagem em presença e das especificidades dos alunos e do professor (SANTOS, 2009, p.57).

Ao assumir a diferenciação pedagógica como uma resposta educativa às necessidades dos estudantes, presume-se que cada um será visto em sua singularidade e Ihes serão oferecidas propostas pedagógicas que favoreçam o seu desenvolvimento. Sabemos que para o planejamento é preciso equipe pedagógica, tempo, espaço físico, recursos materiais; não deixamos de considerar que a realidade mostra que nem sempre as escolas oferecem tais condições, mas são as tentativas e as iniciativas que colocam uma escola em movimento e trazem maior evidência às carências e aos problemas, o que pode gerar busca de soluções.

Outro aspecto referente à diferenciação que requer atenção é o cuidado que se deve ter para que as ações não sejam interpretadas pelos colegas de classe, por docentes, e até pelas famílias, como discriminações negativas ou como superproteção, o que é comum (MARIN, 2015).

Há situações vivenciadas, mais de uma vez, na prática pedagógica, em que ações diferenciadas, planejadas para um aluno com deficiência intelectual, por exemplo, o colocaram numa situação de evidência, em que os colegas de turma, os professores e ele próprio sentiram-se desconfortáveis. 
Em se tratando dos colegas, o sentimento deles era de que estavam sendo prejudicados, porque não receberam o mesmo "benefício", como mais tempo para realizar uma avaliação. Em relação aos professores, o sentimento era de dúvida e sensação de injustiça, ao se questionarem se a diferenciação pedagógica realizada estava adequada: se era muito fácil, o aluno não demonstrou novos conhecimentos, ou se muito difícil, pode ter escamoteado suas reais aprendizagens, demonstrando só impossibilidades. Por fim, o sentimento do próprio aluno quando perguntou "por que o meu trabalho é diferente dos colegas?" e, em outra ocasião, manifestou "isso não é pra mim, é muito difícil, eu não sei fazer" (MARIN, 2015).

Essas situações surgiram em contextos escolares onde os profissionais e alunos estão aprendendo a lidar com a diversidade e a diferenciação. Mais uma vez, evidencia-se que tais episódios apontam para a formação de uma nova cultura; docentes precisam olhar para si (nos incluímos nisso) e verificar que os limites e problemas não estão somente fora de nós. Ferreira (2013, p. 82) discute isso de modo esclarecedor:

[...] ao tratar dos conceitos de diversidade e diferença há que se considerar a subjetividade e a intersubjetividade que constituem nossa relação com o outro/a porque a diversidade e a diferença que nos caracterizam como iguais não estão 'lá fora', desligadas de quem somos, mas aqui, presentes no nosso agora existencial. Entender essa premissa é chave quando o foco de atenção está colocado sobre grupos vulneráveis, uma vez que o enfrentamento de problemas, tais como exclusão, violência e discriminação, implica assumir que o 'problema' que os afeta (o/a outro/a que acreditamos ser diferente de nós por suas marcas identitárias) 'não está lá', mas em cada um que perpetra a violência ou se cala diante da violação de seus direitos garantidos por meio de legislação vigente.

Diferenciação pedagógica requer projetos curriculares que concebam recursos variados, estratégias individualizadas, ajustes para uma educação sob medida que não sejam considerados estranhos ao cotidiano. O que se propõe aqui é um currículo para a diversidade, conforme, ainda, argumenta Ferreira (2013, p. 88-89):

Ao tratar de um currículo para a diversidade, então, argumento que este deve ser um currículo para os direitos humanos e, considerandose que os currículos são constituídos por um conjunto de conhecimentos e práticas pedagógicas articulados a um tempo e 
espaço histórico específicos, cujas dinâmicas são reinterpretadas cotidianamente na escola, o currículo da educação básica deste nosso tempo e espaço deve reconhecer a diversidade, promover os direitos humanos e a inclusão de todos/as.

Essa concepção de currículo se articula com as demandas de cada grupo num contexto determinado, envolve conhecimentos teóricos e práticos, em que as diferenciações pedagógicas se inserem, justamente, porque se coadunam com a diversidade.

Tomlinson (2008, p.7) faz uma discussão sobre diferenciação pedagógica e diversidade, refletindo que o interesse sobre o tema deve ter sido suscitado "pela tomada de consciência de já não ser possível olhar para uma turma e fingir que os alunos são essencialmente parecidos":

Há cada vez mais alunos a serem diagnosticados como tendo défice de atenção e outras desordens relacionadas. Um diagnóstico de dificuldade de aprendizagem específica afecta os alunos virtualmente em todas as turmas. Para além disso, os alunos chegam às salas de aula com capacidades e níveis de compreensão elevados. Apresentam um número de handcaps físicos. Representam culturas diversas. [...] Isso implica numa retomada sobre as práticas de ensino, no contexto escolar, modificar ou diferenciar o ensino para alunos com níveis de preparação e interesses diferentes, significa, igualmente, maior conforto, empenho e interesse. Inevitavelmente, um tipo de ensino 'pronto a vestir - tamanho único' não irá servir - exatamente como acontece com roupas de tamanho único - a alunos com diferentes necessidades (p. 7-9).

Projetos pedagógicos elaborados de modo a promover ensino de qualidade para todos requer planejamentos em um formato não linear. Aqui podemos pensar na imagem de um itinerário (planejamento) com várias alternativas de percursos, com atalhos, paradas, transportes diferenciados, com acesso por água, terra ou ar. Essa metáfora está sendo usada para compreender que Desenho Universal para a Aprendizagem é uma concepção a ser aplicada em um planejamento curricular. E por quê?

Desenho Universal para a Aprendizagem (DUA) é uma perspectiva educacional que se inspirou em princípios ligados a outras áreas, como arquitetura e engenharia, e envolve a concepção de produtos, ambientes, 
programas e serviços a serem usados, na maior medida possível, por todas as pessoas, sem necessidade de adaptação ou projeto específico.

O design universal para a aprendizagem é alcançado por meio de materiais e atividades curriculares flexíveis, que proporcionam alternativas para os alunos com diferentes capacidades. Essas alternativas são incorporadas ao planejamento inicial, não são acrescentadas depois (VALLE; CONNOR, 2014, p. 96).

Ao buscarmos reflexões sobre currículo e diferenciação, encontramos a concepção referente ao DUA, inicialmente nas informações disponibilizadas pelo Center for Applied Special Technology - CAST (MEYER; ROSE; GORDON, 2014), que propõe o desenvolvimento curricular a partir da redução de barreiras ao ensino e à aprendizagem, de modo que o ensino é planejado com objetivos, criação de materiais, elaboração de estratégias e formas de avaliação que sirvam a todos e a cada estudante. Além disso, um dos princípios fundamentais dessa perspectiva é manter altas expectativas em relação a todos os alunos, incluindo os que apresentam alguma deficiência ou diferença significativa.

Ou seja, a finalidade é o desenvolvimento de práticas pedagógicas que permitam o acesso ao currículo, a participação e o progresso de todos os alunos, independentemente das suas capacidades. Isso significa que o "currículo em ação" irá de encontro às diferenças e necessidades de todos os estudantes, os obstáculos pedagógicos serão removidos para que haja acessibilidade curricular.

Os autores Valle e Connor (2014) possibilitaram que fizéssemos uma reflexão a partir dos princípios do DUA e, ao pensar no nosso cotidiano da educação básica, levantamos algumas questões. Queremos compartilhar, a seguir, o Quadro 1 com os princípios do DUA, explicação e alguns exemplos - ideias adaptadas do material estudado - e, na última coluna, perguntas elaboradas por nós, que compõem nossas inquietações e nos ajudam a pensar melhor. 
QUADRO 1 - Princípios e práticas de DUA

\begin{tabular}{|c|c|c|c|}
\hline PRINCÍPIO & DUA & EXEMPLOS & QUESTÕES \\
\hline 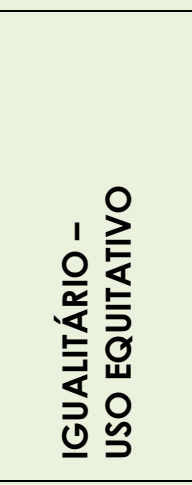 & $\begin{array}{l}\text { O ensino é planejado } \\
\text { para ser útil e acessível } \\
\text { para pessoas com } \\
\text { capacidades diversas. } \\
\text { Os mesmos meios } \\
\text { podem ser } \\
\text { proporcionados a todos } \\
\text { os estudantes e, quando } \\
\text { não for possível, um } \\
\text { meio equivalente deve } \\
\text { ser proporcionado. }\end{array}$ & $\begin{array}{l}\text { Audiolivros, legendas em } \\
\text { qualquer vídeo, leitores } \\
\text { de tela, intérprete de } \\
\text { Libras. }\end{array}$ & $\begin{array}{l}\text { Audiolivros, filmes, } \\
\text { documentários e } \\
\text { programas legendados, } \\
\text { leitor de tela devem ser } \\
\text { disponibilizados para } \\
\text { todos? } \\
\text { Quando fazemos isso? }\end{array}$ \\
\hline 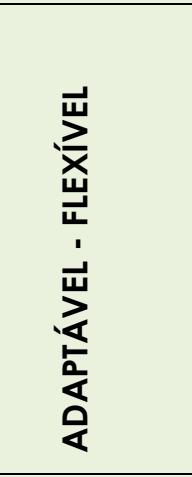 & $\begin{array}{l}\text { O ensino é planejado } \\
\text { para acomodar uma } \\
\text { variedade de } \\
\text { capacidades } \\
\text { individuais. O docente } \\
\text { deve dar oportunidade } \\
\text { de escolha aos } \\
\text { estudantes. }\end{array}$ & $\begin{array}{l}\text { Informações podem ser } \\
\text { acessadas em variadas } \\
\text { fontes - livros, } \\
\text { documentos, } \\
\text { internet/sites, entrevistas. } \\
\text { Uma tarefa escolar } \\
\text { pode ser realizada por } \\
\text { meio de uma } \\
\text { apresentação oral, de } \\
\text { um texto escrito, de uma } \\
\text { imagem. }\end{array}$ & $\begin{array}{l}\text { Qual é a base para que } \\
\text { um ensino seja flexível? } \\
\text { Como garantir diversas } \\
\text { possibilidades de } \\
\text { participação } \\
\text { diversificada dos } \\
\text { estudantes? }\end{array}$ \\
\hline 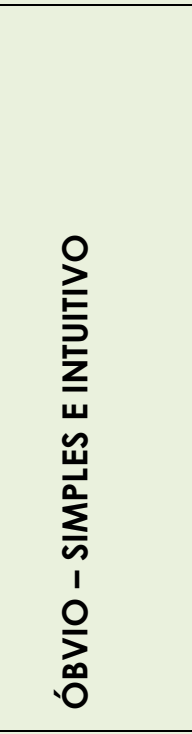 & $\begin{array}{l}\text { O ensino é planejado de } \\
\text { uma maneira direta e } \\
\text { fácil de entender. }\end{array}$ & $\begin{array}{l}\text { Informações claras } \\
\text { fornecidas para todas as } \\
\text { tarefas - de modo oral, } \\
\text { escrito e com imagem. } \\
\text { Materiais devem ser } \\
\text { fáceis de acompanhar - } \\
\text { objetivos, organizados. } \\
\text { A participação do } \\
\text { estudante deve ser } \\
\text { claramente } \\
\text { determinada (fazer } \\
\text { anotações, opinar } \\
\text { oralmente...). } \\
\text { O apoio de colegas ou } \\
\text { do docente pode ser } \\
\text { disponibilizado durante } \\
\text { as tarefas. }\end{array}$ & $\begin{array}{l}\text { Como não confundir } \\
\text { simplificação e clareza } \\
\text { com minimização } \\
\text { curricular? }\end{array}$ \\
\hline
\end{tabular}




\begin{tabular}{|c|c|c|c|}
\hline PRINCÍPIO & DUA & EXEMPLOS & QUESTÕES \\
\hline 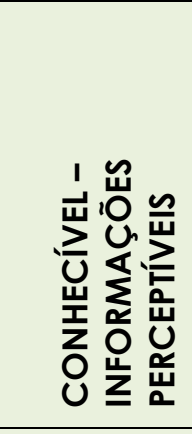 & $\begin{array}{l}\text { O ensino é planejado de } \\
\text { modo que as } \\
\text { informações/ } \\
\text { conteúdos/conceitos } \\
\text { sejam acessíveis a todos. }\end{array}$ & $\begin{array}{l}\text { Materiais escritos } \\
\text { disponibilizados de } \\
\text { forma digital, impressa, } \\
\text { com fonte ampliada. As } \\
\text { aulas podem ser } \\
\text { gravadas. Legendas } \\
\text { estão presentes em } \\
\text { todas as mídias. } \\
\text { Tradutores na internet } \\
\text { podem ser acionados. }\end{array}$ & $\begin{array}{l}\text { Precisamos esperar ter } \\
\text { um estudante cego, } \\
\text { disléxico, surdo, } \\
\text { estrangeiro ou } \\
\text { deficiente intelectual } \\
\text { para preparar materiais } \\
\text { acessíveis? }\end{array}$ \\
\hline 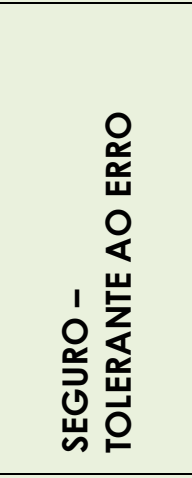 & $\begin{array}{l}\text { O ensino é planejado } \\
\text { com previsão das } \\
\text { variações no ritmo das } \\
\text { aprendizagens } \\
\text { individuais dos } \\
\text { estudantes e } \\
\text { considerando as } \\
\text { habilidades de cada um }\end{array}$ & $\begin{array}{l}\text { Aulas de apoio, material } \\
\text { online para revisão e } \\
\text { reforço, orientação às } \\
\text { famílias para apoiar o } \\
\text { estudante. } \\
\text { Trabalhos entregues por } \\
\text { partes para feedback e } \\
\text { revisão. } \\
\text { Complexidade da } \\
\text { tarefa pode ser } \\
\text { modificada. }\end{array}$ & $\begin{array}{l}\text { Como evitar a } \\
\text { frustração ou pouco } \\
\text { desempenho do } \\
\text { estudante ao oferecer } \\
\text { tarefas difíceis demais, } \\
\text { que não realize, ou } \\
\text { fáceis demais, que } \\
\text { cause desinteresse? }\end{array}$ \\
\hline 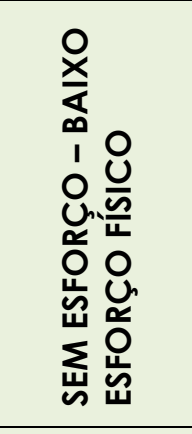 & $\begin{array}{l}\text { O ensino é planejado } \\
\text { para evitar o esforço } \\
\text { físico desnecessário, a } \\
\text { fim de permitir o máximo } \\
\text { de atenção voltada à } \\
\text { aprendizagem. }\end{array}$ & $\begin{array}{l}\text { Organização do espaço } \\
\text { físico que garanta a } \\
\text { circulação com } \\
\text { facilidade para } \\
\text { qualquer um. Uso de } \\
\text { ledor nas avaliações. } \\
\text { Consulta à tabuada. Uso } \\
\text { da calculadora. Banco } \\
\text { de palavras. Textos em } \\
\text { formato digital ou áudio. }\end{array}$ & $\begin{array}{l}\text { Estudantes, em geral, } \\
\text { precisam de muito } \\
\text { esforço físico e } \\
\text { extenuação, demonstrar } \\
\text { cansaço para provarem } \\
\text { que estão estudando? } \\
\text { Somente as atividades } \\
\text { muito dinâmicas ou } \\
\text { cinestésicas cansam? }\end{array}$ \\
\hline 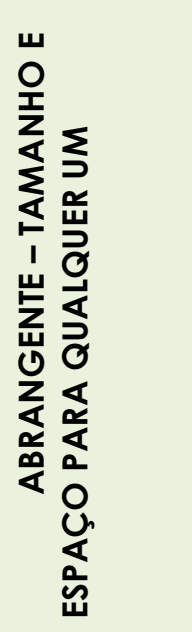 & $\begin{array}{l}\text { O ensino é planejado de } \\
\text { modo que recursos, } \\
\text { espaços, materiais } \\
\text { possam ser ajustados. }\end{array}$ & $\begin{array}{l}\text { Disposição das carteiras } \\
\text { pode mudar: } \\
\text { semicírculo, círculo, } \\
\text { fileiras, grupos. } \\
\text { Mesas que sirvam para } \\
\text { destros e canhotos. } \\
\text { Superfícies de trabalho } \\
\text { que podem ficar em } \\
\text { níveis diferentes. } \\
\text { Maçanetas de fácil } \\
\text { manuseio em portas e } \\
\text { armários. } \\
\text { Tamanhos de letras, } \\
\text { folhas, cadernos, lápis. }\end{array}$ & $\begin{array}{l}\text { Como interferir na } \\
\text { organização, escolha, } \\
\text { compra de materiais de } \\
\text { uso escolar? }\end{array}$ \\
\hline
\end{tabular}




\begin{tabular}{|c|c|c|c|}
\hline PRINCÍPIO & DUA & EXEMPLOS & QUESTÕES \\
\hline 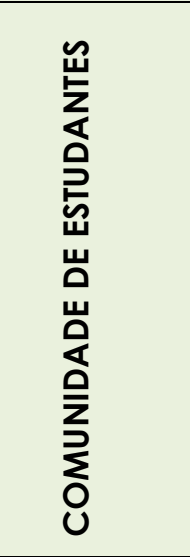 & $\begin{array}{l}\text { O ensino é planejado de } \\
\text { modo a promover a } \\
\text { interação e } \\
\text { comunicação entre } \\
\text { todos os estudantes e } \\
\text { entre estudantes e } \\
\text { docentes. }\end{array}$ & $\begin{array}{l}\text { Propostas de trabalho } \\
\text { com a turma toda, ou } \\
\text { em grupos, ou em } \\
\text { duplas e também com } \\
\text { instruções } \\
\text { individualizadas. } \\
\text { Todos sabem o nome de } \\
\text { todos e conhecem } \\
\text { habilidades e talentos } \\
\text { de cada um. } \\
\text { O diálogo é } \\
\text { deliberadamente } \\
\text { promovido. }\end{array}$ & $\begin{array}{l}\text { Como se constitui uma } \\
\text { comunidade/coletivo } \\
\text { de estudantes? O que é } \\
\text { importante para isso? } \\
\text { Qual o papel docente } \\
\text { nesse contexto? }\end{array}$ \\
\hline 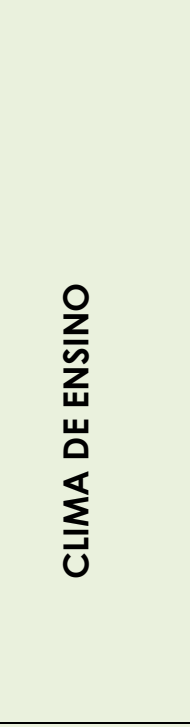 & $\begin{array}{l}\text { O ensino é planejado } \\
\text { para ser acolhedor e } \\
\text { para todos (inclusivo). } \\
\text { Há expectativas } \\
\text { elevadas em relação a } \\
\text { todos os estudantes - } \\
\text { espera-se que todos } \\
\text { aprendam muitas } \\
\text { coisas. Aprender o que } \\
\text { não sabia. }\end{array}$ & $\begin{array}{l}\text { Criação de um } \\
\text { ambiente acolhedor, } \\
\text { com respeito à } \\
\text { diversidade. } \\
\text { Os planejamentos de } \\
\text { ensino expressam a } \\
\text { concepção de } \\
\text { diversidade em seus } \\
\text { objetivos. } \\
\text { O feedback específico } \\
\text { é dado de modo } \\
\text { contínuo ao estudante. } \\
\text { As expectativas sobre o } \\
\text { seu desempenho são } \\
\text { informadas aos } \\
\text { estudantes de forma } \\
\text { clara, e são altas. }\end{array}$ & $\begin{array}{l}\text { Como se estabelece o } \\
\text { clima de ensino? } \\
\text { Compete a quem } \\
\text { promover um bom } \\
\text { clima? }\end{array}$ \\
\hline
\end{tabular}

Fonte: elaboração das autoras, já publicado em outro material (MARIN; BRAUN, 2018).

Essas análises e organização de ideias fortaleceram práticas já realizadas, aperfeiçoaram outras e possibilitaram avançar com novas propostas. Descreveremos algumas de modo mais geral e apresentaremos um exemplo de modo mais detalhado, como forma de ilustrar que há possibilidades a serem discutidas nas escolas visando o caminho para garantir uma escola para todos.

\section{DO CURRÍCULO PRATICADO}

Com destaque para as demandas apresentadas para estudantes com Deficiência Intelectual (DI) e Transtorno do Esprectro do Autismo (TEA), ao longo de alguns anos temos desenvolvido ações que inicialmente eram 
implantadas depois do planejamento curricular pronto, porém mais recentemente estão sendo incorporadas aos planejamentos iniciais, mesmo que timidamente e com a necessidade de constante diálogo. Ainda assim, vemos movimento e constituição de uma nova cultura escolar se configurando, que no planejamento de ensino busca prever acessibilidade ao currículo (previamente) e não adaptação curricular (posteriormente).

Lembrando que 'adaptação curricular' tem sido um conceito bastante difundido como resposta educativa às necessidades educacionais de estudantes que apresentam um desenvolvimento peculiar. O termo e sua aplicação ganharam repercussão, principalmente, a partir da publicação de um documento oficial denominado "Parâmetros curriculares nacionais: Adaptações Curriculares" (BRASIL, 1998), que teve um papel impulsionador para pensar formas diferentes de organização curricular.

No entanto, vimos, no decorrer dos anos, esse conceito ser aplicado de modo prático como uma minimização do currículo, principalmente para estudantes com deficiência intelectual, ou seja, adaptações como 'cortes' nos conteúdos e até nos objetivos, levando quase à elaboração de um currículo paralelo, o que não era a proposição. Sem prolongar essa discussão, queremos esclarecer o porquê de nos colocarmos favoráveis à expressão 'acessibilidade ao currículo' em detrimento à 'adaptação curricular'. Entendemos acessibilidade para o mesmo currículo, com estratégias de diferenciação, que são disponibilizdas para toda a turma, baseadas em pressupostos de Desenho Universal para a Aprendizagem, e não uma adaptação curricular exclusiva para este ou aquele estudante.

Listamos algumas ações a serem destacadas como diferenciações, numa perspectiva em construção de um currículo marcado pelo Desenho Universal para a Aprendizagem. Todos os exemplos a seguir têm como base - currículo escolar, partem dele e buscam atingir os objetivos finais propostos.

- Elaboração de objetivos diferenciados em relação ao tempo escolar, ou seja, alguns estudantes têm seus objetivos adequados às suas aprendizagens em andamento, 
independente do ano escolar que frequentam, pois há componentes curriculares e conceitos que levam mais tempo a serem construídos, e não será a retenção ou reprovação que garantirá a aprendizagem.

- Diversificação de instrumentos e de estratégias de avaliação: provas e testes realizados com consulta ao material impresso; provas dialogadas, ou seja, conduzidas a partir de interlocução e interação verbal com um docente; avaliações orais; instrumentos de avaliação em leitura fácil, com enunciados diretos, destaques de palavras, apoio com imagens, banco de palavras e outros recursos para garantir maior autonomia; construção de critérios diferenciados de correção. Essas possibilidades ainda não são disponibilizadas a todos os estudantes, mas poderia haver maior difusão e melhor composição com variados instrumentos, a serem escolhidos pelos estudantes, para compor uma avaliação. Lidamos, porém, com mecanismos arraigados na escola que ainda teremos muito o que discutir e reformular.

- Aplicação do sistema de ensino colaborativo, promovendo a mediação de um segundo docente em sala durante as aulas; há uma literatura variada com experiências interessantes: Capellini (2004); Capellini e Mendes (2007); Castro, Almeida e Toyoda (2007); Ferreira, Mendes Almeida e Del Prette (2011); Damiani (2008); Fenty, Mcduffie-Laudrm e Fisher (2012); Machado e Almeida (2010); Braun (2012); Marin e Braun (2011); Mendes, Vilaronga e Zerbato (2014).

- Recursos que seriam usados exclusivamente por um estudante, em função de suas necessidades, sendo ofertados para a turma toda: audiolivro; vídeos; material tátil; maquetes; esquemas.

- Elaboração, em cooperação com os própios estudantes, de mapas conceituais, resumos, resenhas, pesquisas, realizados em 
aulas de apoio, fora do turno escolar e depois disponibilizados para a turma, durante as aulas.

- Trazer para uma aula, que seria ministrada somente a partir de material impresso e explicação oral, outros elementos, tais como: vídeos com legenda, imagens com audiodescrição, jogos e desafios, experimentos, para dar alguns exemplos. Desse modo, é possível atender uma maior diversidade de estilos de aprendizagem e potenciais variados.

Aparentemente parecem ser coisas comuns e corriqueiras, mas não são, pois "a escola, pela sua obrigatoriedade, nos leva a conviver com a diferença de modo intenso, mas a nega com práticas homogeneizadoras e, com isso, costuma mascarar a diferença evidenciando o diferente" (SERPA; RIBEIRO, 2015, p. 98).

Segue, agora, um exemplo, descrito com maiores detalhes, para demonstrar o que entendemos por uma proposta curricular com diferenciação pedagógica associada à perspectiva do Desenho Universal para a Aprendizagem. A descrição compreende uma atividade desenvolvida em uma turma de $4^{\circ}$ ano do ensino fundamental, de uma escola pública, composta por 20 estudantes, entre eles um com autismo e uma com deficiência intelectual.

A atividade envolveu a elaboração de um relatório, após a realização de uma expedição pedagógica denominada "Circuito Ludi"3. Tal proposição abordou de forma integrada vários componentes curriculares, envolvendo conhecimentos de história, geografia e linguagem, prioritariamente. Todavia, as áreas de matemática e ciências permearam os momentos de ensino e aprendizagem, na medida em que aspectos como

\footnotetext{
3 A expedição faz alusão ao nome "Ludi" pelo fato das discussões e atividades utilizarem como recurso didático principal a coleção literária de autoria de Luciana Sandroni e outros autores, que traz a narrativa de vários fatos históricos do Brasil, a partir das aventuras de uma menina chamada Ludi em viagens no tempo. Ludi é a protagonista de uma série que se iniciou em 1989, entre os títulos estão: "Ludi: na Chegada e no Bota-Fora da Família Real" e "Ludi na Revolta da Vacina". O Circuito Ludi é uma atividade de campo realizada no centro da cidade do Rio de Janeiro, com o objetivo principal de compreeder como a cidade se formou.
} 
datas, períodos de tempo, conceitos de ciências sobre eventos históricos como "A revolta da Vacina", entre outros, também estavam presentes.

O Circuito Ludi é uma atividade de campo, que denominamos como 'expedição', pelo centro da cidade do Rio de Janeiro, com visitação a vários pontos históricos, tais lugares remetiam aos textos trabalhados previamente em sala de aula, de acordo com o planejamento de ensino para o ano escolar.

Todo o percurso da expedição foi planejado antecipadamente com os estudantes, com informações prévias para orientar as observações sobre os locais. Durante o trajeto, para que os estudantes com Autismo e DI tivessem a possibilidade de resgatar informações e elaborar associações sobre o que discutiram em sala e o que viam naquele momento atual, foi usado um fichário de imagens que traziam o nome do lugar e um ou dois fatos relevantes associados. Assim, a cada ponto de parada, o fichário podia ser acessado por qualquer estudante e, a partir dele, um diálogo era melhor constituído com colegas e professores.

Além disso, docentes fotografaram os estudantes em cada ponto de observação e também os estudantes fizeram registros fotográficos por conta própria. As imagens captadas durante a expedição, no decorrer das semanas seguintes em sala de aula, serviram de apoio ao resgate das informações para elaborar os registros do relatório.

O relatório, como uma tipologia textual com características específicas, é considerado uma produção de texto significativa, com atenção à descrição da sequência e dos fatos observados e ocorridos. Era comum o relatório ser construído por elaboração escrita individual, com ilustrações feitas por cada estudante da turma. Dada essa configuração, foi observado que o tipo de produção habitual demandaria uma elaboração das informações num tempo que não qualificava o modo de produção dos estudantes com Autismo e DI, naquele momento. Articulou-se, então, com a turma a configuração de um formato diferente para o relatório e a proposta foi elaborar, individualmente, um álbum sanfonado com páginas que 
apresentassem uma linha sequencial de informações com imagens, legendas e textos, um formato que melhor atenderia a todos os estudantes.

Nesse contexto, a mediação pedagógica se constituiu tanto a partir de ações planejadas pelas professoras do Núcleo Comum ${ }^{4}$ e do Atendimento Educacional Especializado (AEE) ${ }^{5}$, como da aprendizagem colaborativa entre pares. A atividade acabou por apresentar um perfil que atendeu demandas para a participação, aprendizagem e elaboração das proposições dos estudantes com DI e Austimo, mas que também atendeu às expectativas relativas ao ensino e à aprendizagem dos demais estudantes da turma.

O material final, ainda que na sua produção longitudinal demandasse mediações pedagógicas significativas para os dois estudantes, teve uma configuração que os aproximou daquilo que seus colegas produziram, sendo percebido pela turma como um formato que possibilitou a todos compreender, relacionar, organizar e produzir conhecimentos sobre os conteúdos curriculares abordados.

\section{PARA CONCLUIR POR AQUI, MAS SEM TERMINAR}

Neste debate, abordar os pressupostos de diferenciação pedagógica e de Desenho Universal para a Aprendizagem requer a problematização sobre 'a escola para todos' e "todos na escola" (RODRIGUES, 2003).

'Todos na escola' é escola aberta, acessível, com matrícula disponível, que tem a diversidade presente nos seus bancos, no seu "chão", no seu cotidiano. E 'escola para todos' é garantir a permanência dessa diversidade, sem processos de exclusão ou tentativas de tornar todos 'iguais'.

Estar na escola é uma das etapas para o processo de escolarização, mas a garantia de construção de conhecimentos que gera desenvolvimento

\footnotetext{
${ }^{4}$ A escola em que o exemplo da atividade descrita se configura denomina usualmente os docentes regentes das turmas do Ensino Fundamental $\mathrm{I}-1^{\circ}$ ao $5^{\circ}$ ano - como professores do Núcleo Comum.

5 Os professores do Atendimento Educacional Especializado atuam na elaboração do planejamento e na regência da turma, a partir do sistema do Ensino Colaborativo.
} 
é dada com a participação efetiva e com a aprendizagem de cada e de todos os estudantes.

Cabe aos educadores viabilizarem o processo escolar dos estudantes com deficiência ou com outra condição de desenvolvimento que seja diferente do esperado, de modo que a escolarização seja favorável aos demais estudantes também - 'escola para todos'.

$\mathrm{Na}$ ausência de estratégias ou proposições diferenciadas para e no coletivo, o que se revela é uma 'escola com todos' e não 'para todos', onde nem todos usufruem das suas proposições. Isso nos alerta para os índices escolares de retenção, evasão, discrepância idade-série, sem nem precisar citar o estudante com deficiência intelectual ou com autismo.

A mudança ou a revisão das práticas curriculares se dá nesse sentido, de se constituir em uma proposta didático-pedagógica que amplie as possibilidades de participação e de aprendizagem, uma 'escola para todos'.

É um desafio que está posto e, por isso, declaramos que:

Mudanças nunca acontecem enquanto as pessoas estão ocupadas sendo sensíveis e realistas. Elas acontecem quando ousamos imaginar o mundo de modo diferente e nos arriscamos a mudá-lo de acordo. Para os críticos que talvez nos acusem de "sonhadores", saibam que escolhemos ficar do lado da imaginação e apostar na chance de fazer uma diferença (VALLE; CONNOR, 2014, p. 13).

Não deixamos de ser "sensíveis e realistas" ao que está ao nosso redor; desenvolvemos nosso trabalho docente cotidiano a partir do que vivenciamos e daquilo que nos move. No entanto, para além do real e sensível, olhamos prospectivamente e imaginamos "o mundo de modo diferente e nos arriscamos a mudá-lo". Neste texto, tentamos partilhar das nossas experiências e reflexões acerca de um currículo para a diversidade e com ela, o que pressupõe planejamentos de ensino que não precisam ser 'adaptados' para os estudantes com deficiência, mas elaborados de modo que todos e cada um, que estão na sala de aula, tirem o maior proveito 
possível de recursos e estratégias planejados para garantir acessibilidade ao currículo.

Falamos, então, disso: de acessibilidade ao currículo e não de adaptação curricular. O que imaginamos de diferente é um currículo que atenda a todos que estão na escola desde a sua concepção, desse modo, teremos uma 'escola para todos'.

\section{REFERÊNCIAS}

AAIDD. Asociación Americana de Discapacidades Intelectuales y del Desarrollo. Discapacidad Intelectual: definición, clasificación y sistemas de apoyo. $11^{a}$ Edición. Madri: Editorial Alianza, S.A., 2011.

ANDRÉ, M. A pedagogia das diferenças. In: ANDRÉ, M. (org.). Pedagogia das diferenças na sala de aula. Campinas: Papirus, 1999, p. 11-26.

BRASIL. Secretaria de Educação Fundamental. Parâmetros curriculares nacionais: Adaptações Curriculares. Secretaria de Educação Fundamental. Secretaria de Educação Especial. Brasília: MEC/SEF/SEESP, 1998.

BRAUN, P. Espaços-tempo de ensino e aprendizagem no contexto da escola para todos: reflexões a partir de cenas de um cotidiano. In. PLESTCH, M.; RIZO, G. Cultura e formação: contribuições para a prática docente. Rio de Janeiro: Editora da UFRRJ, 2010, p. 38-48.

BRAUN, P. Uma intervenção colaborativa sobre os processos de ensino e aprendizagem do aluno com deficiência intelectual. 2012. 324f. Tese (Doutorado em Educação) - Faculdade de Educação, Universidade do Estado do Rio de Janeiro, Rio de Janeiro, 2012.

BRAUN, P.; MARIN, M. Recortes do cotidiano: a inclusão pensada a partir de um espaço educacional de excelência. In: PLETSCH, M. D.; ZINER, A. (orgs.). Educação Especial. Seropédica: Edur, 2011, p. 1-12.

BUENO, J. G. S.; LEHMKHUL, M. de S.; GOES, R. S de. A Relação Público/Privado nas Políticas de Educação Especial no Período Ditatorial no Brasil (1964-1985). Arquivos Analíticos de Políticas Educativas, v. 27, n. 62, p. 123, 2019.

CAPELLINI, V. L. M. F. Avaliação das possibilidades do ensino colaborativo no processo de inclusão escolar do aluno com deficiência intelectual. 2004. 300f. Tese (Doutorado em Educação Especial), Centro de Educação e Ciências Humanas, Universidade Federal de São Carlos, São Carlos (SP), 2004. 
CAPELLINI, V. L. M. F; MENDES, E. G. O Ensino Colaborativo favorecendo o desenvolvimento para a inclusão escolar. Educere et Educare, UNIOESTE, Cascavel (PR), v. 2, n. 4, p.113-128, 2007.

CASTRO, S. F.; ALMEIDA, M. A.; TOYODA, C. Y. Ensino Colaborativo: uma proposta de intervenção em uma sala de aula do ensino regular com alunos com deficiência incluídos. Anais. IV Congresso Brasileiro Multidisciplinar de Educação Especial, 2007. Disponível em: <http://www.uel.br/eventos> Acesso em: janeiro de 2019.

DAMIANI, M. F. Entendendo o ensino colaborativo em educação e revelando seus benefícios. Revista Educar, Curitiba: Editora UFPR, n. 31, p. 213230, 2008. Disponível em: < http://www.scielo.br/pdf/er/n31/n31al3> Acesso em: junho de 2019.

DMS - 5. Manual diagnóstico e estatístico de transtornos mentais. Porto Alegre: Artmed, 2014.

FENTY, N. S.; MCDUFFIE-LAUDRM, K.; FISHER, G. Using collaboration, coteaching, and question answer relationships to enhance content area literacy. Teaching Exceptional Children, v. 44, n. 6, p. 28-37, 2012.

FERREIRA, B. C.; MENDES, E. G.; ALMEIDA, M. A.; DEL PRETTE, Z. A. P. Parceria colaborativa: descrição de uma experiência entre o ensino regular e especial. Revista Educação Especial, Santa Maria, nov. 2011 Disponível em: https://periódicos.ufsm.br/educacaoespecial/article/view/4137Acesso em:julho de 2019.

FERREIRA, W. B. "Pedagogia das Possibilidades": é possível um currículo para a diversidade nas escolas brasileiras? cadernoscenpec, São Paulo, v.3, n.2, p.73-98, jun 2013. Disponível em:

<http://cadernos.cenpec.org.br/cadernos/index.php/cadernos/article/viewF ile/230/255>Acesso em: julho de 2019.

GARCÍA, M. T.; BEATÓN, G. A. Necessidades educativas especiais: desde o enfoque histórico-cultural. São Paulo: Linear, 2004.

GIMENO SACRISTÁN, J. A cultura para os sujeitos ou os sujeitos para a cultura? O mapa mutante dos conteúdos na escolaridade. In: GIMENO SACRISTÁN, J. Poderes instáveis em educação. Porto Alegre: ArtMed, 1999, p. 147-206.

GIMENO SACRISTÁN, J. O currículo: os conteúdos do ensino ou uma análise prática. In: GIMENOSACRISTÁN J.; PÉREZ GÓMEZ, A. I. Compreender e transformar o ensino. 4. ed. Porto Alegre: ArtMed, 2000, p. 119-148.

GIMENO SACRISTÁN, J. O Currículo: uma reflexão sobre a prática. Madri: Morata, 1991. 
JANNUZZI, G. S. de M. A educação do deficiente no Brasil: dos primórdios ao início do século XVI. São Paulo: Autores Associados, 2006.

MACHADO, A. C.; ALMEIDA, M. A. Parceria no contexto escolar: uma experiência de Ensino Colaborativo para educação inclusiva. Revista Psicopedagogia, São Paulo, v. 27, n. 84, p. 344-351, 2010.

MAGALHÃES, R. de C. B. P. falem com elas: construir diálogos na escola inclusiva. In. MAGALHÃES, R. de C. B. P. (Org.). Educação Inclusiva:

escolarização e formação docente. Brasília: Liber Livro, 2011, p. 13-33.

MAGALHAES, R. de C. B. P.; SOARES, M. T. N. Currículo escolar e deficiência: contribuições a partir da pesquisa-ação colaborativo-crítica. Cadernos de Pesquisa, São Paulo, v. 46, n. 162, p. 1124-1147, Dec. 2016. Disponível em: <http://www.scielo.br/scielo.php?script=sci_arttext\&pid=s010015742016000401 124\&lng=en\&nrm=iso>. Acesso em: julho 2019.

MARIN, M. Inclusão escolar de alunos com necessidades educacionais especiais no segundo segmento do ensino fundamental em um espaço de excelência acadêmica. 2015. 193f. Tese (Doutorado em Educação),

Faculdade de Educação, Universidade do Estado do Rio de Janeiro, Rio de Janeiro, 2015.

MARIN, M.; MASCARO, C. A. de A. C.; MARETTI, M. M. B.; BRAUN, P. Inclusão escolar sob o viés do ensino colaborativo: uma experiência em três instituições públicas. Revista e-Mosaicos, [S.I.], v. 4, n. 7, p. 52 - 62, jul. 2015. Disponível em: <https://www.e-publicacoes.uerj.br/index.php/emosaicos/article/view/17120>. Acesso em: 24 abr. 2019.

MARIN, M.; BRAUN, P. Desenho universal para a aprendizageme diferenciação curricular. Boletim de educação especial e inclusão escolar. Universidade Federal Rural do Rio de Janeiro. Observatório de Educação elnclusão Escolar: práticascurriculares e processos de ensino e aprendizagem (ObEE). Ano 2, v. 2, p. $11-14,2018$.

MENDES, E. G.; VILARONGA, C. A. R.; ZERBATO, A. P. Ensino colaborativo como apoio à inclusão escolar: unindo esforços entre educação comum e especial. São Carlos: EdUFSCar, 2014.

MEYER, A.; ROSE, D.H.; GORDON, D. Universal design for learning: Theory and Practice. Wakefield, MA: CAST Professional Publishing, 2014.

MORGADO, J. C. Para um outro arquétipo de escola: a necessidade de mudar as políticas e as práticas curriculares. Educação em Revista, Belo Horizonte, v. 26, n. 02, p.15-42, 2010. 
Nunes, C., Madureira, I., Desenho Universal para a Aprendizagem:

Construindo práticas pedagógicas inclusivas, Da Investigação às Práticas, n. 5, v. 2, p.126 - 143, 2015. Disponnível em:

www.scielo.mec.pt/pdf/inp/v5n2a08.pdf Acesso em: julho de 2019.

PERRENOUD, P. Pedagogia diferenciada: das intenções à ação. Porto Alegre: Artmed Editora, 1999.

PERRENOUD, P. A pedagogia na escola das diferenças: fragmentos de uma Sociologia do fracasso. Porto Alegre: Artmed Editora, 2001.

RODRIGUES, A. J. Contextos de aprendizagem e integração/inclusão de alunos com necessidades educacionais especiais. In: RIBEIRO, M. L.; BAUMEL, R. (orgs). Educação Especial: do querer ao fazer. São Paulo: Avercamp, 2003.

RODRIGUES, D. Equidade e educação inclusiva. Portugal: PROFEDIÇÕES/ Jornal A Página, 2013.

ROLDÃO, M. do C. Diferenciação curricular e inclusão. In: RODRIGUES, David (org.). Perspectivas sobre inclusão: da educação à sociedade. Portugal: Porto Editora, 2003a, p. 151-165.

ROLDÃO, M. do C. Diferenciação curricular revistada - conceito, discurso e práxis. Portugal: Porto Editora, 2003b.

SANTOS, L. Diferenciação pedagógica: um desafio a enfrentar. Revista Noesis - Reflexão e acção, n. 79, p. 52-57, out 2009. Disponível em: <http://www.dgidc.min-edu.pt/index.php?s=directorio\&pid=172> Acesso em: 05 de março de 2013.

SAVIANI, N. Currículo: um grande desafio para o professor. Revista de Educação, São Paulo, n.16, p. 35-38, 2003.

SERPA, A.; RIBEIRO, S. da S. Currículo: conversando sobre diferentes e diferenças. Revista Teias, [S.I.], v. 16, n. 40, p. 89-98, mar. 2015. Disponível em: <https://www.epublicacoes.uerj.br/index.php/revistateias/article/view/24552/ 17532>. Acesso em: 24 mar. 2019.

TOMLINSON, C. A. Diferenciação pedagógica e diversidade. Ensino de alunos em turmas com diferentes níveis de capacidades. Porto Alegre, 2008.

VALLE, J. W.; CONNOR, D. J. Ressignificando a deficiência: da abordagem social às práticas inclusivas na escola. Porto Alegre: AMGH, 2014.

Recebido em: 30 de julho de 2019 Aprovado em: 25 de novembro de 2019 